\title{
Urdimento
}

Revista de Estudos em Artes Cênicas

E-ISSN: 2358.6958

\section{Para além do quadro: intersecções entre o trabalho de Tadeusz Kantor e o pensamento de Aby Warburg}

Igor Gomes Farias

Laura Wilbert Gedoz

Maria de Fátima de Souza Moretti

\section{Para citar este artigo:}

FARIAS, Igor Gomes; GEDOZ, Laura Wilbert; MORETTI, Maria de Fátima de Souza. Para além do quadro: intersecções entre o trabalho de Tadeusz Kantor e o pensamento de Aby Warburg. Urdimento, Florianópolis, v. 1, n. 40, mar./abr. 2021.

do DOI: http:/dx.doi.org/10.5965/1414573101402021e0202 
Para além do quadro: intersecções entre o trabalho de Tadeusz Kantor e o pensamento de Aby Warburg

Igor Gomes Farias ${ }^{1}$

Laura Wilbert Gedoz ${ }^{2}$

Maria de Fátima de Souza Moretti ${ }^{3}$

\begin{abstract}
Resumo
Este artigo buscou identificar os cruzamentos entre o trabalho artístico de Tadeusz Kantor e o pensamento de Aby Warburg. A partir de uma análise da obra kantoriana, influenciada por sua relação com as artes plásticas, foi ressaltado seus evidentes pontos de aproximação com a lógica por trás do Atlas Mnemosyne. Reconhecendo a imagem como o ponto central dos paralelos enfatizados aqui, refletiu-se sobre como os ensinamentos de Warburg contribuem para a leitura de obras artísticas posteriores a ele. Deste modo, destacou-se o método da montagem e de associação de imagens, bem como as importantes relações empregadas por Didi-Huberman ao retomar Warburg nas discussões contemporâneas da história da arte.
\end{abstract}

Palavras-chave: Imagem. Tadeusz Kantor. Aby Warburg. Montagem. Constelação.

Beyond the frame: intersections between the work of Tadeusz Kantor and Aby Warburg's thinking

\begin{abstract}
This article aimed to identify the intersections between the artistic work of Tadeusz Kantor and the thought of Aby Warburg. From an analysis of Kantor's work, influenced by its relationship with the plastic arts, it's evident points of approximation with the logic behind the Mnemosyne Atlas were emphasized. Recognizing the image as the central point of the parallels emphasized here, it was reflected on how Warburg's teachings contribute to the reading of artistic works after him. Thus, the method of assembly (montage) and association of images was highlighted here, as well as the important relations used by Didi-Huberman when he returns to Warburg in contemporary discussions of art history.
\end{abstract}

Keywords: Image. Tadeusz Kantor. Aby Warburg. Assembly. Constellation.

${ }^{1}$ Mestrando do programa de pós graduação em Literatura (PPGLit) da Universidade Federal de Santa Catarina (UFSC), com orientação de Paulo Ricardo Berton e coorientação de Maria de Fátima de Souza Moretti. Bolsista CAPES. Ator e pesquisador. igorgomes1605@gmail.com

(9) http://lattes.cnpq.br/2851591723776841 $\quad$ (iD https://orcid.org/0000-0001-7585-3380

2 Mestranda do programa de pós graduação em Literatura (PPGLit) da Universidade Federal de Santa Catarina(UFSC), com orientação de Paulo Ricardo Berton e coorientação de Maria de Fátima de Souza Moretti. Bolsista CAPES. Atriz e pesquisadora. Laurawilbertgedoz@gmail.com

(9) http://lattes.cnpq.br/0251684400121354 $\quad$ (iD) https://orcid.org/0000-0003-4955-4410

${ }^{3}$ Profa. PhD. do curso de Artes Cênicas, Universidade Federal de Santa Catarina (UFSC). Diretora e marionetista. sassamoretti@gmail.com

http://lattes.cnpq.br/9087678319013848

https://orcid.org/0000-0002-4740-3718 
Más allá del marco: intersecciones entre la obra de Tadeusz Kantor y el pensamiento de Aby Warburg

\section{Resumen}

Este artículo buscó identificar las intersecciones entre la obra artística de Tadeusz Kantor y el pensamiento de Aby Warburg. A partir de un análisis de la obra kantoriana, influido por su relación con las artes plásticas, se destacaron sus evidentes puntos de aproximación con la lógica detrás del Atlas Mnemosyne. Reconociendo la imagen como el punto central de los paralelos enfatizados aquí, se reflexionó sobre cómo las enseñanzas de Warburg contribuyen a la lectura de obras artísticas posteriores a él. Así, se destacó aquí el método de ensamblaje y asociación de imágenes, así como las importantes relaciones empleadas por Didi-Huberman al retomar Warburg en las discusiones contemporáneas sobre la historia del arte.

Palabras clave: Imagen. Tadeusz Kantor. Aby Warburg. Ensamblaje. Constelación. 
Falar de imagem é, antes de tudo, se abrir a significações diversas que foram incorporadas por nós ao longo da história. Desde as definições mais antigas do termo "imagem”, como a de Platão em A República (século IV a.C.), se atribui a ela uma relação estreita com o processo de representação (Martine Joly, 2012) e um espelhamento daquilo que viria do real. No campo artístico, essa noção foi bastante fecunda e parece ser intrínseca especialmente à representação visual. No entanto, transformações distintas ocorreram nos últimos séculos e seguem seu curso na atualidade, quando assistimos a uma proliferação cada vez maior de imagens. Os adventos da fotografia e, posteriormente, do cinema certamente trouxeram uma mudança profunda nas discussões sobre o tema (Jacques Aumont, 2012), que foram aprofundadas pela semiótica e por diversos movimentos que fizeram do século passado um terreno fértil para analisar a representação e tudo que a circunda.

Na busca por nomes que percorrem tais deslocamentos ao se trabalhar a imagem no século XX, sobretudo no campo artístico, encontramos no encenador polonês Tadeusz Kantor (1915-1990) um abundante campo de estudo. Colecionando atividades que mesclam a pintura, a escrita, o teatro e a performance, e especialmente graças a sua importante raiz nas artes plásticas, ele consagrou um trabalho que encontra na imagem a potencialidade máxima para elaborar a cena. Sua obra nos aponta para uma fértil experimentação em torno da imagem, dialogando com históricas figuras que tão bem souberam pensá-la no século passado, como é o caso de um dos mais célebres estudiosos da área nesse período, o alemão Aby Warburg (1866-1929). Assim, inspirados numa leitura atenta de Didi-Huberman (1953) na atualidade, propomos neste artigo paralelos entre o teatro kantoriano e a obra de Warburg. Partindo de um mergulho pelo seu Atlas Mnemosyne (1924) e expandindo nossa atenção para outras explorações do historiador, a escolha aqui se revela também como uma provocativa tentativa de nos aproximarmos metodologicamente do sistema warburguiano.

De início, torna-se importante concentrarmos nossa atenção sobre Kantor. O encenador traz para seu teatro todas as suas especificidades enquanto "observador-pintor", sendo altamente inspirado pelas vanguardas do século XX, e, 
desse modo, concretiza na cena experimentos que parecem se justificar especialmente por esse olhar sensível que as artes plásticas o instruíram. Segundo Cintra, ele "insiste em afirmar que seu teatro não é um teatro de pintor, mas que a pintura é uma espécie de escrita para o teatro" (Wagner Cintra, 2010, p. 90). Uma das características que mais se destacam em seus trabalhos é o emprego de materialidades nas cenas, onde objetos miseráveis são elevados à categoria de obra de arte, prática que está intimamente ligada ao que faz em seus quadros e à ampla influência dos movimentos do dadaísmo e do construtivismo. Assim, guarda-chuvas, envelopes e demais objetos dão a impressão (muitos deles chegaram a fazer concretamente isso, vide Figura 2) de se deslocarem para fora da moldura para quem os aprecia, provocando algo que o polonês também busca em sua cena.

Nos espetáculos, Kantor propõe a convergência de vetores de força, gerando fricções, estranhamentos. O que acontece em cena refrata a energia geradora; rearticulam-se imagens, distorcidas e derrisórias, em sequências descontínuas de flashes. Não se trata, porém de mera sucessão que vise produzir um quadro animado por explosivos choques imagísticos. Em seu teatro, Kantor trabalha uma dinâmica tal que exclui a recepção contemplativa da imagem (Jacob Guinsburg, 2008, p. XIX).

Produzindo arte com advindos dadaístas, Kantor tem nos trabalhos de Marcel Duchamp (1887-1968) inspiração, principalmente em sua obra mais conhecida, Fonte, de 1917. Provocadora, a produção Dada é uma rica exploração do inconsciente com consciência, a favor da desordem e do caos. A construção poética mediante colagens de revistas e jornais produz diferentes montagens e formas de leitura. Esses elementos do acaso e da montagem são visíveis nas peças do artista polonês, destacando-se nessa fase dadaísta as peças Balladyna (1942), de Juliusz Slowacki, inspirada pela Bauhaus, e O Retorno de Ulisses (1944), de Stanisław Wyspiański. Também influenciado pelo movimento dadaísta, Kantor busca uma arte que choque os padrões da sociedade da época ao compor objetos cênicos com materiais antigos e abandonados, tachados de obsoletos, dando-os um ressignificado. Ele flerta com uma analogia entre a eternidade da arte e a degradação da matéria, joga com o que é transitório, salvando aquilo que não tem 
mais utilidade (mas possuidor de uma trajetória), tirando das ruas o que restou para convertê-lo em algo eterno.

Como artista plástico, Tadeusz Kantor também pinta diversos trabalhos de caráter figurativo, que, como em sua carreira no teatro, constituem fases diversificadas. Durante os anos 1940, produz quadros de estética pesada, com cores e tons escuros, aparência ríspida e inúmeras silhuetas de aspecto grotesco. Após essa fase, entram as pinturas de poucos tons frios, azulados, de composições metafóricas. É sabido que Kantor, nos anos 50, pinta telas tachistas, termo que vem do francês, tache, de caráter drástico. Um estilo sem forma, improvisado, de um espontâneo instintivo, com cores vibrantes e pinceladas violentas. No fim dos anos 60, Kantor cria obras em alto-relevo com embalagens compostas por objetos (guarda-chuvas, sacos, pacotes e envelopes) aplicados em tela, em uma espécie de ritual que procura conferir existência a eles ali, despojando-os de sua função vital (Kantor, 2008). Como expressão artística, Kantor os posiciona ao lado de figuras humanas, que reagem aos objetos apenas por sua materialidade. Durante as décadas de 70 e 80, ele passa a se dedicar mais ao teatro, embora a parte plástica continue refletindo nos palcos, em uma série de produções.

Figura 1 - Embalagem: guarda-chuva e personagens de Tadeusz Kantor (1967)

Figura 2 - Wrzesień 1939 de Tadeusz Kantor - Foto: Krzysztof Karolczyk ${ }^{5}$

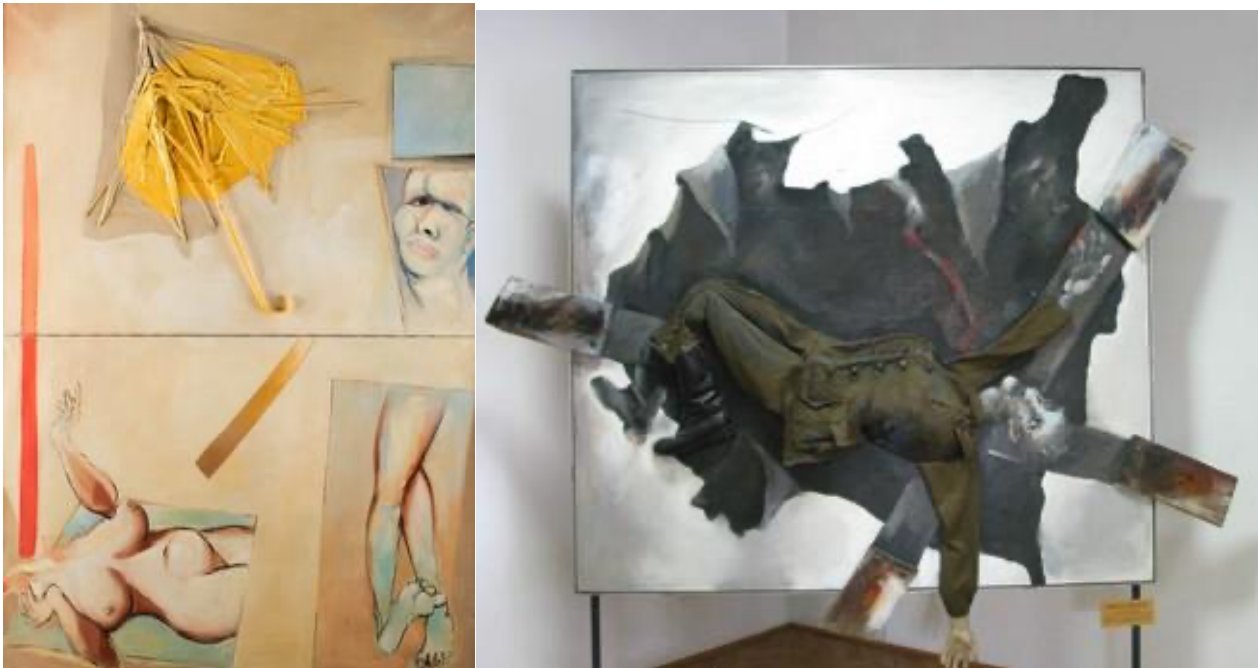

4 Disponível em: https://www.polswissart.pl/pl/aukcje/archiwalne/205-aukcja-dziel-sztuki/8878-ambalazparasol-i-postacie. Acesso em: 5 mar. 2020.

${ }^{5}$ Disponível em: https://culture.pl/pl/galeria/prace-tadeusza-kantora-galeria. Acesso em: 5 mar. 2020. 
O processo que Kantor aplica a suas pinturas, dando relevos e extrapolando os limites da tela, e o exercício de tirar de seu público a mera função de contemplador de imagens são os primeiros indícios que nos guiam a pensar em algo muito semelhante ao que podemos identificar no trabalho de Warburg. Mais que isso, também evidenciam outras importantes percepções que surgem no século XX, especialmente após o advento do cinema, como os modelos epistemológicos de quadro e montagem. De acordo com Sergei Eisenstein (2002), a ideia do quadro se traduz como sendo os fotofragmentos da natureza, enquanto a montagem seriam as múltiplas combinações desses distintos fotofragmentos lógica fortemente inspirada pelo procedimento cinematográfico. Assim, o quadro e a montagem são aspectos da arte que, mesmo sendo diferentes, estão interligados, pois trabalham em conjunto. As reproduções fixas do quadro podem ser combinadas de várias formas, alcançando diferentes resultados, da verossimilhança até a total distorção.

O plano é uma célula da montagem. Exatamente como as células, em sua divisão, formam um fenômeno de outra ordem, que é o organismo ou embrião, do mesmo modo no outro lado da transição dialética de um plano há a montagem. O que, então caracteriza a montagem e, consequentemente, sua célula - o plano? A colisão. O conflito de duas peças em oposição entre si. O conflito. A colisão (Eisenstein, 2002, p. 42).

Preocupado com uma nova atmosfera na cena, que na maioria das vezes consiste em desarmar o teatro de sua própria necessidade de ilusão (ou seja, no esconder de seus próprios recursos técnicos), Kantor desenvolve um trabalho centralizado na composição de imagens fortes e repetitivas. Tal atitude acompanha mudanças profundas daquele momento, rompendo com a tradição de um teatro objetivado especialmente na materialização do texto em cena. Em outras palavras, um teatro hierarquizado, realista, onde o texto e o ator se sobressaem entre os elementos teatrais. O polonês modifica completamente esse modelo em seu trabalho.

De acordo com Hans-Thies Lehmann, o teatro kantoriano opera uma supressão do drama em função de uma poesia de imagens na cena. Assim, "o 
dramático se perde em favor de imagens em movimento por meio do ritmo repetitivo, das configurações à maneira de quadros e de uma certa desrealização dos personagens" (Lehmann, 2007, p. 120). Retirando totalmente a hierarquia entre os elementos cênicos, Kantor dá a mesma importância para o ator, o texto, a luz, os objetos, os figurinos, a cenografia, etc., fazendo todos trabalharem em proveito de uma marcante dramaturgia visual da cena.

A cena kantoriana é um espaço onde a hibridez se consagra como uma linguagem bem própria e ao que assistimos é um teatro onde tudo parece ser arquitetado sobre as bases firmes da criação imagética, num ambiente onde o texto é estabelecido junto com os outros elementos, que trabalham para a efetivação do jogo e de algo muito próximo do ritualístico. Ao assistirmos a um espetáculo de Kantor, é como se cada imagem criada pudesse dialogar com a outra, numa esfera superior, firmando, assim, uma leitura além da individualidade de cada uma delas, onde o híbrido se torna regra para a criação. É assim que Kantor trabalha com sua imaginação e sua efervescente memória, efetivando aquele relampejar teorizado por Walter Benjamin (1892-1940) num contexto marcado pelas lembranças da guerra e de uma infância na Polônia do início do século XX. Aliás, são justamente esses os temas mais presentes no teatro do encenador, que a cada espetáculo dá movimento a suas reminiscências individuais e coletivas, convidando seu público a embarcar com ele num retrabalhar constante nos traumas do século.

\begin{abstract}
Em suas produções, o passado é estruturado como memória naquilo que tem de descontínuo e aparece como um arranjo de imagens de diferentes períodos superpostos uns sobre os outros; sua ordem não é determinada por uma cronologia, mas por emoções e pelo fluxo de livres associações que delas decorrem. Kantor chamava essas imagens de "placas de memória" e as incluía na dialética da vida e da morte - a qual é muito peculiar tanto a seu próprio trabalho quanto à fotografia e ao ato de fotografar (Jarosław Suchan, 2015, p. 61).
\end{abstract}

O conflito e a colisão parecem tão bem descrever o teatro de Kantor, espaço arquitetado especialmente sobre as bases do dualismo existencial entre vida e morte. As imagens, como na peça A Classe Morta (1975), são distorcidas e 
friccionadas, forçando atritos e tensões que geram incômodo no espectador. A peça não tem um formato lógico, não é como uma sequência de imagens que geram uma significação, contando uma história. As unidades dessa sequência de quadros estão nos temas tratados no espetáculo, que as conectam entre si através da leitura individual do espectador, abrindo um mundo de possibilidades de compreensão. Para Kantor, afinal, "a arte não segue um processo puramente formal e linear, mas é movimento permanente e transformação de pensamentos e ideias. [...]. O que mais importa é o poder de gerar novas ideias" (Christine Greiner, 2015, p. 91). Eis uma característica que nos guia perfeitamente a outra exploração que firma a potente aproximação deste artigo. Afinal, não podemos encontrar aqui semelhanças fundamentais com a lógica por trás do atlas de Warburg?

Como um potente instrumento capaz de materializar suas principais teorias, Aby Warburg elabora a partir de 1924 seu Atlas Mnemosyne, que é também uma perfeita reflexão histórica acerca do método da montagem. Com suas "histórias de fantasmas para gente grande", maneira pela qual o próprio autor apelidou carinhosamente suas imagens, ele nos apresenta 63 pranchas (que comportavam 971 imagens em sua totalidade) deslocadas de cronologia, períodos, hierarquias e demais convenções da história da arte, algo que, de início, já podemos relacionar profundamente com tudo aquilo apontado até aqui sobre Kantor, que elabora a cena justamente sob os princípios da suspensão de sua linearidade, da montagem. No atlas do alemão, vemos se efetivar um deslocamento em direção ao pensamento de uma "ciência da cultura", que aposta essencialmente na busca de uma história das imagens ligada a uma "transversalidade do saber", unindo assim aspectos históricos, antropológicos, psicológicos, filosóficos e estéticos.

A montagem [...] não está orientada simplesmente, a montagem escapa às teleologias, torna visíveis as sobrevivências, os anacronismos, os encontros de temporalidades contraditórias que afetam cada objeto, cada acontecimento, cada pessoa, cada gesto. Então, o historiador renuncia a contar "uma história" mas, ao fazê-lo, consegue mostrar que a história não é senão todas as complexidades do tempo, todos os estratos da arqueologia, todos os pontilhados do destino (Didi-Huberman, 2012, p. 112). 
Sabe-se que para elaborar a montagem das imagens do Atlas Mnemosyne (vide Figura 4) Warburg se inspira na mesma lógica de organização de sua biblioteca, que seguia os preceitos da "boa vizinhança". Na obra, o agrupamento de variadas imagens, organizadas por distintos temas, é determinante para a ativação de forças nelas contidas. Ou seja, acima de tudo se destaca aqui o ato da escolha do artista, que, além de reunir imagens próprias, reproduções de pintura, arte gráfica e escultura, utiliza carpetes, painéis genealógicos, fragmentos de jornais e de publicidade, e outras imagens que trazem com elas certa impureza daquilo que para ele é recalcado pela sociedade. Movimentos que dialogam perfeitamente com Kantor, que, como vimos, busca nas lixeiras e nos resquícios da guerra aquilo que aparentemente não teria mais serventia, permitindo uma nova simbologia aos objetos miseráveis ao agregá-los a seu teatro - igualmente desinteressado em simplesmente contar uma história.

Warburg tão bem sabe excluir do espectador a mera função contemplativa e, assim como Kantor, expõe com maestria as complexidades no trabalhar com imagens. A própria incompletude de seu atlas (que deveria ter 79 pranchas em vez de apenas 63) é até hoje um dos fatores mais fascinantes ao se pensar essa obra, característica que também nos permite um constante reatualizar dela e que segue nos encaminhando a Kantor, igualmente interessado numa obra nunca capaz de chegar à estagnação. Para o encenador, "o que muda não são os elementos e as coisas, mas as conexões" (Greiner, 2015, p. 89), estas primordiais para a leitura dos painéis warburguianos. Não por acaso, também destacando a importância do processo artístico em contrapartida da necessidade de um produto finalizado, Kantor realiza em 1963 um dos experimentos que melhor ilustram sua aproximação com Warburg. Sua chamada Antiexposição ocorre na Galeria Krzystofory, em Cracóvia, e surge acompanhada de um manifesto que explicita bem o que o polonês busca com ela: 


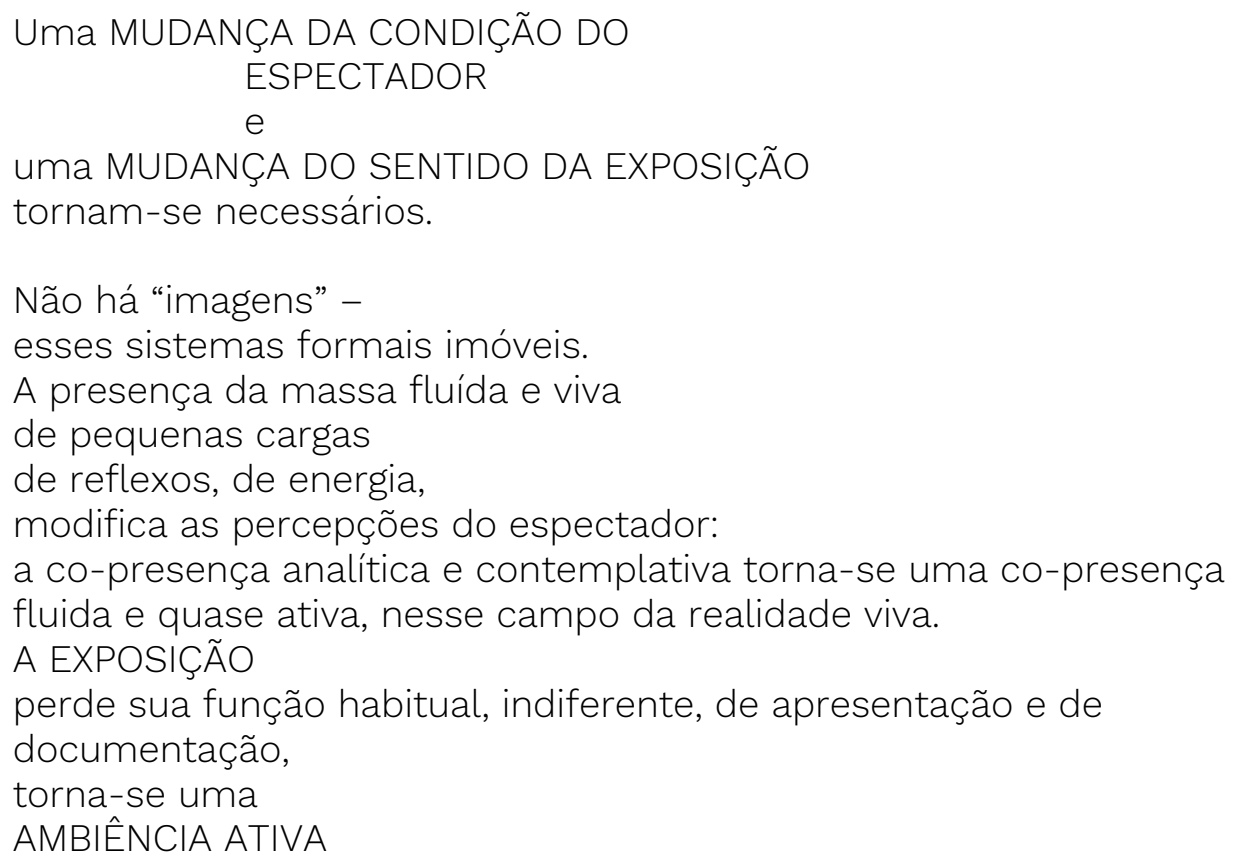

(Kantor, 2008, p. 106)

De modo semelhante ao Atlas Mnemosyne, Kantor cria uma exposição (vide Figura 3) onde o que está exposto pode fugir completamente do convencional em uma galeria de arte tradicional. Estão dispostos pelo ambiente mais de 900 objetos (fotografias, mapas, esboços, cartas, prescrições médicas, tíquetes, etc.), que, a princípio, como em Warburg, parecem se destacar ainda mais pelo conjunto do que por suas individualidades. "Era o resultado do trabalho de um ano de preparações, de manobras de todo um processo de mudanças que se produziam nesse momento em minhas concepções da obra de arte, de sua função e de seu destino", afirma Kantor (2008, p. 105). Assim, o polonês questiona a essência daquele ato, dando destaque a tudo aquilo que está nesse meio do caminho de "se tornar algo". Seu interesse é justamente a mobilidade das peças, que, enquanto não finalizadas, revelam sua potência como fonte para toda criação. 
Figura 3 - Antiexposição de Tadeusz Kantor na Galeria Krzystofory, Cracóvia (1963) Foto: Chrzanowski Tadeusz ${ }^{6}$

Figura 4 - Atlas Mnemosyne de Aby Warburg, 1928-29

Foto: The Warburg Institute London?

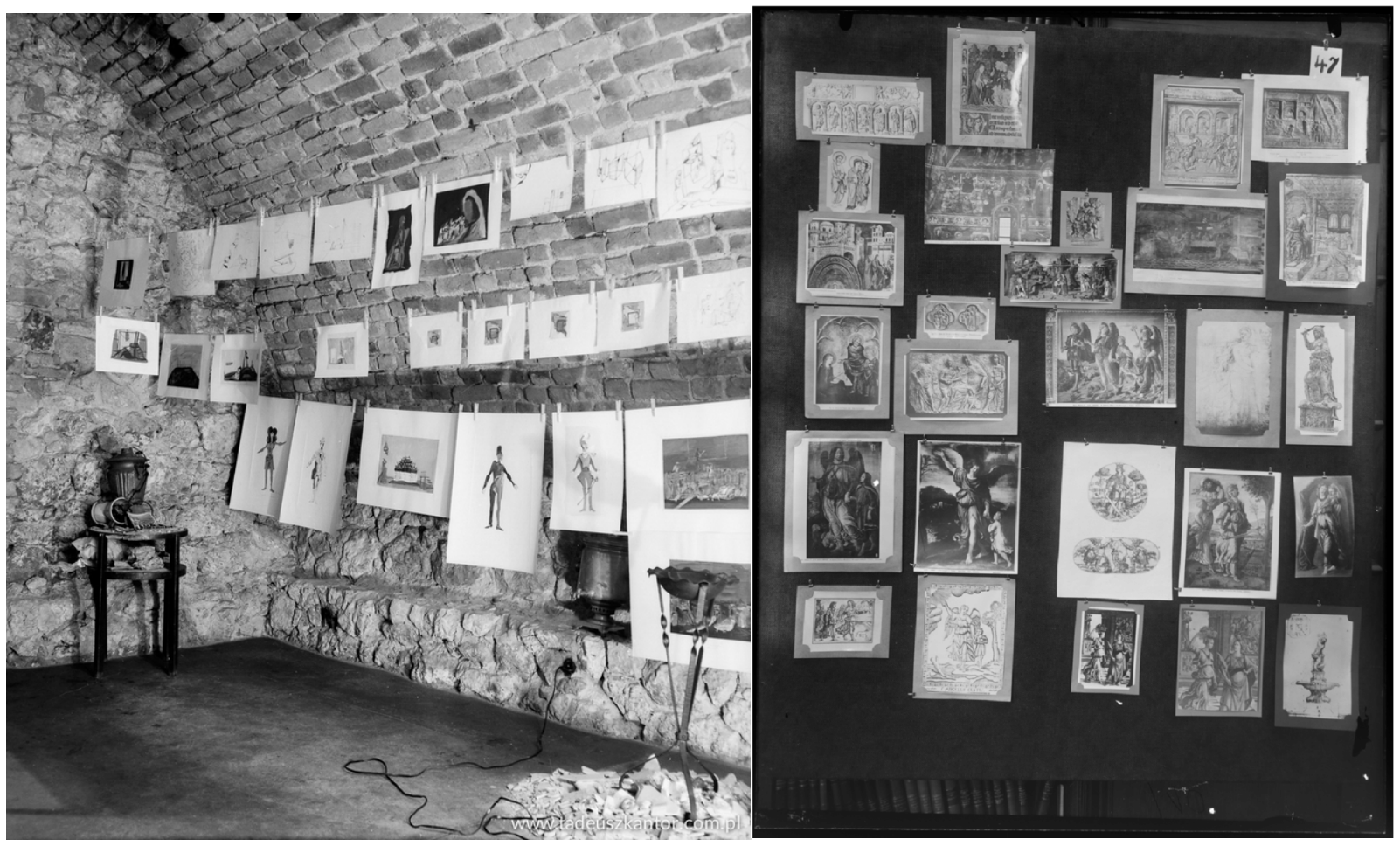

Kantor parece tão bem atualizar o legado de Warburg, acima de tudo propondo novos olhares para o espectador e para a imagem - não vista mais como algo imóvel. Para Suchan (2015, p. 42), "o objetivo da exposição não era o de dar uma visão geral de suas realizações, aqueles sistemas formais coagulados, mas o de fornecer um recipiente preenchido da matéria fluida da vida”, que, para o encenador, era a grande matéria-prima de toda criação. Portanto, era preciso criar outras relações com esse material, as quais ocorrem agora no que Kantor chamará de sua primeira "ambiência". Desse modo, na Antiexposição pulsa aquela essência

${ }^{6}$ Disponível em: https://bit.ly/2DNJPQz. Acesso em: 5 dez. 2019.

${ }^{7}$ Disponível em: https://bit.ly/2OSSNIT. Acesso em: 5 dez. 2019. 
da colisão na montagem, que evidencia, assim, todas as camadas de suas fissuras, dialogando perfeitamente com a obra warburguiana.

Não somente o atlas, desde Warburg, modificou em profundidade as formas - logo, os conteúdos - de todas as "ciências da cultura", ou ciências humanas, como também incitou um grande número de artistas a repensar completamente, sob a forma da coleção e da remontagem, as próprias modalidades segundo as quais as artes visuais são hoje elaboradas e apresentadas (Didi-Huberman, 2018, p. 23).

É evidente que o trabalho de Warburg tem inspirado muitos artistas e pesquisadores ao longo da história. Não sabemos, além de mera especulação, se é possível detectar uma relação direta entre seu legado e o trabalho de Kantor, mas é certo o quanto aquele continuou a inspirar tantos outros nomes mundialmente. Prova disso é o interesse cada vez maior por seu trabalho na atualidade, que encontra na figura do francês Didi-Huberman um de seus maiores entusiastas. No ano de 2010, o filósofo indica um novo foco sobre a obra de Warburg ao realizar sua exposição Atlas, no Museu Reina Sofía, em Madri. Dessa experiência, igualmente marcada pela analogia entre imagens e pelo conceito de "sobrevivência das formas", nasce também um importante ensaio - que nos servirá como um guia fundamental a partir daqui -, no qual o francês fundamenta seus olhares sobre Warburg. Nele, as discussões se concentram em torno da figura do Atlas, esse titã capaz de sustentar em seus braços a figura do globo terrestre, que tem sua imagem questionada através do diálogo com nomes como Friedrich Nietzsche, Sigmund Freud, Johann Wolfgang von Goethe, Francisco de Goya e Charles Baudelaire.

Warburg se aventura por estudos sobre a mitologia e a astrologia, tendo familiaridade com esses campos. Sua escolha pelo nome e simbologia do titã Atlas também se relaciona a um conhecido gênero epistêmico ligado ao campo da cartografia, com alcance amplo nas ciências da cultura, e sugere uma figura capaz de suscitar inúmeras interpretações sobre o projeto warburguiano como um todo. Assim, Didi-Huberman (2018) afirma que o Atlas Mnemosyne se consagra como um enorme poema visual, que, por meio de imagens, é capaz de evocar, invocar 
ou reconvocar as grandes hipóteses da obra de Warburg. "É de fato à imagem do próprio titã Atlas que o atlas de Warburg pode então se apresentar a nós: como resposta a livre e explosiva - aberta e fecunda - a uma situação de opressão pesada - fechada e estéril - que fora a sua desde o fim da Primeira Guerra" (DidiHuberman, 2018, p. 94). É notório, afinal, que Warburg tenha tido um colapso nervoso nesse período.

Aby Warburg permanece internado em um sanatório, na Suíça, entre 1921 e 1924, como uma possível consequência do impacto que a guerra teve nele. Desse modo, é perceptível como seu atlas acaba sendo uma resposta "ansiosa e genial" a sua realidade, à situação psíquica que ele vivia naquele momento (DidiHuberman, 2018). O historiador adentra, desse modo, no mundo complexo que existe em torno da figura mítica do Atlas, explorando suas distintas significações. O experimento também nos atenta para uma espécie de "nó de temporalidades", evidenciando como Warburg é capaz de transformar sua própria loucura em uma matriz metodológica (Ludueña, 2017). De acordo com sua crença, por exemplo, as guerras seriam provocadas por deuses e demônios espectrais, como uma espécie de intervenção no estado de coisas daqui, resultantes do fato de a humanidade não cumprir uma distância segura das forças sobre-humanas. Assim, DidiHuberman nos aponta a possibilidade de o projeto Mnemosyne ser justamente, naquele momento histórico, essa espécie de resposta a algo que se apresenta como uma tragédia ou punição do destino.

Voltando um pouco a Kantor, percebemos como a guerra parece igualmente estimular o polonês a oferecer respostas para a degradante situação que se concretiza em sua realidade. É a partir da Segunda Guerra Mundial que o encenador inicia sua primeira fase artística, operando clandestinamente em Cracóvia, onde surgem os primeiros esboços de um trabalho que seguirá cada vez mais rearticulando imagens. O teatro kantoriano é essencialmente "um teatro após a catástrofe [...], que vem da morte e expõe uma paisagem para além da morte" (Lehmann, 2007, p. 118). Em certa consonância com Warburg, ele parece também questionar - especialmente por meio do vazio e da repetição - sobre o cruzamento dessa fronteira invisível que nos encaminha a outra catástrofe. No 
entanto, é justamente nessas tais "forças sobre-humanas", rechaçadas por Warburg, que o artista encontra seus melhores aliados, fazendo de seu teatro um possível espaço de encontro com tais espectros.

Há uma razão porque no teatro de Kantor nós estamos continuamente lidando com a repetição: as coisas são repetidas, os mortos voltam à vida, as situações são recriadas de novo, não porque ele quer preencher o tempo em suas produções, mas porque, como ele diz, talvez essa repetição finalmente nos permita ver aquele evento como se fosse pela primeira vez, de modo que nós possamos mudá-lo. O movimento circular não é circular, porque toda vez que ele se repete, talvez, haja um novo aspecto que está sendo trazido à atenção. Há um buraco, para ele (Michal Kobialka, 2005, p. 228).

Como podemos ver até aqui, as imagens do atlas warburguiano contam uma espécie de "história alternativa da história da arte", reunindo temas e formas de distintos períodos. Acima de tudo, elas exemplificam uma capacidade de "desorientação da história", em um processo semelhante ao de Kantor, em que parece ser através da imagem - especialmente sob esse novo prisma sobre ela, de seu buraco - que podemos reler o mundo a nossa volta. Com seu atlas, Warburg "introduz no saber a dimensão sensível, o diverso, o caráter lacunar de cada imagem" (Didi-Huberman, 2018, p. 19). Essa é uma mudança que surge fundamentalmente da revolta do alemão com uma mera história estetizante da arte, defendendo o anacronismo das imagens, que também o guia sempre a novos rumos em suas pesquisas. Entre as vivências dele, por exemplo, se destaca uma importante viagem ao território dos índios Pueblo, nos Estados Unidos. Aliás, é justamente sobre essa vivência que o alemão falará em uma conferência dentro do sanatório, que tem como objetivo provar sua sanidade para uma plateia de médicos e psicanalistas.

A figura do Atlas já está presente logo na segunda prancha do Mnemosyne, representado pela célebre escultura Atlas Farnèse (vide Figura 5), que também sublinha certo caráter primitivo de seu experimento. Na mitologia, os titãs (doze deuses do Olimpo) tomam o mundo, dando aos homens aquilo que os deuses guardavam como privilégio - sendo posteriormente punidos por isso. Sua simbologia também se relaciona à imagem do "carregador" ou "suporte" do 
cosmos, trazendo consigo tanto a potência como o sofrimento de suportá-lo. É importante nos atentarmos que tal simbologia introduz perfeitamente os princípios que, para Warburg, são os mais potentes em uma imagem. Afinal, a dialética inerente à imagem é o que mais lhe interessa, sendo um elemento que destaca as outras múltiplas polaridades que a compõem. Segundo DidiHuberman, o Atlas possui um “saber trágico”, um conhecimento adquirido através da dor. É apenas pelo castigo imposto a ele que aprende sobre o cosmos. Eis aqui, portanto, a dualidade entre força e sofrimento - modelo que ganha uma atenção especial de Warburg em seus estudos e que, para ele, é capaz de tão bem personificar os polos da grandeza e da impotência do homem.

Figura 5 - Escultura Atlas Farnèse, Nápoles, s. II d.C. ${ }^{8}$

Figura 6: Embalagem "homem carregando malas" de Tadeusz Kantor, 1967 Foto: Edgar Watpor ${ }^{9}$

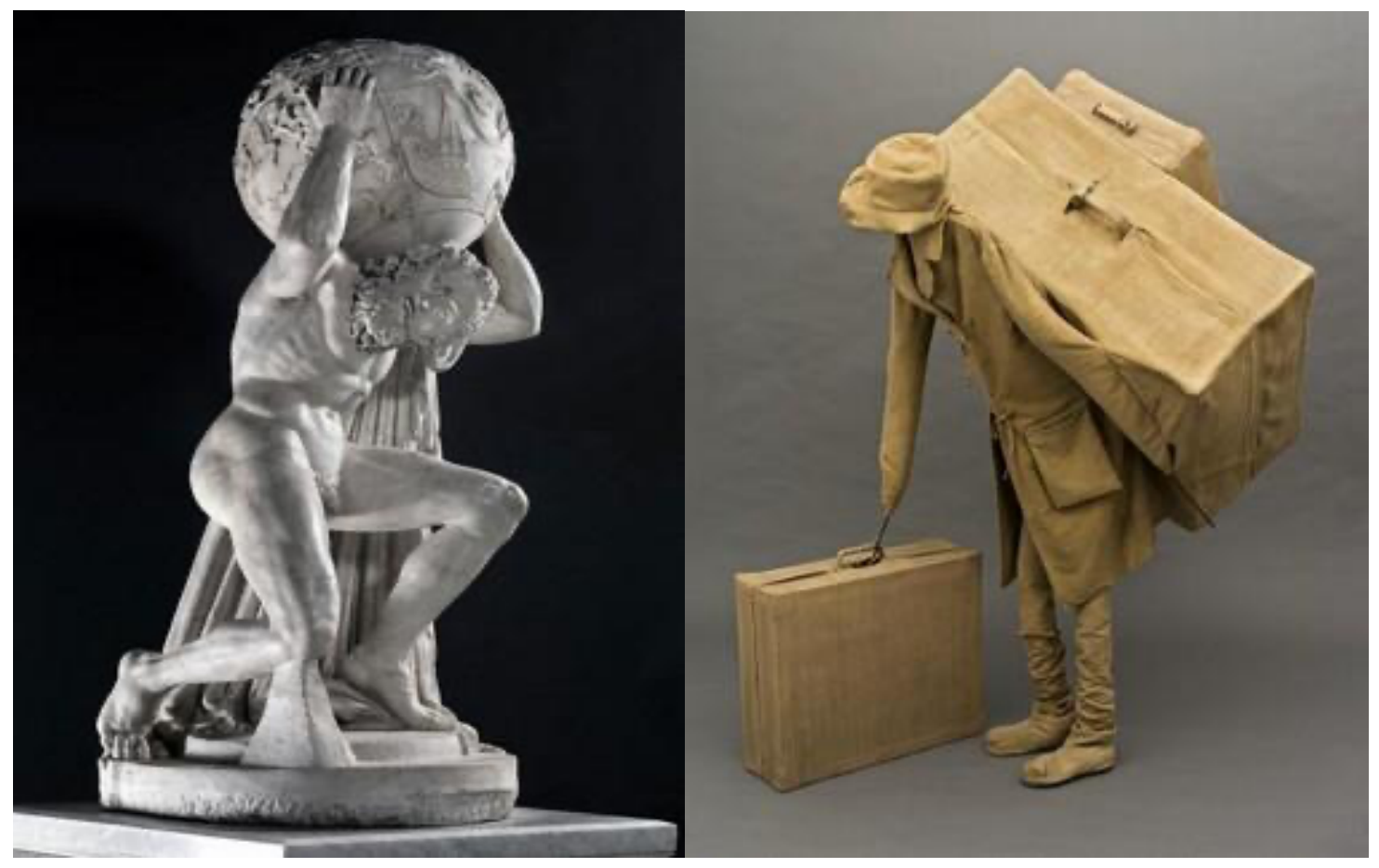

Nesse ponto, Kantor também parece lidar perfeitamente com essa dialética apontada por Warburg. Afinal, os princípios que norteiam seu teatro a espelham

\footnotetext{
${ }^{8}$ Disponível em: https://www.italianways.com/rebel-gods-punishment-the-farnese-atlas/. Acesso em: 5 dez. 2019.
}

${ }^{9}$ Disponível em: https://zasoby.msl.org.pl/arts/view/175. Acesso em: 5 dez. 2019. 
totalmente. Aqui, a figura de um curioso personagem-embalagem (vide Figura 6), seu "homem carregando malas", já nos revela desde o início um intrigante paralelo com a figura do Atlas. Ele surge em diferentes produções kantorianas, como no espetáculo A Galinha D'Água (1967), parecendo atualizar tão bem esse signo utilizado por Warburg. Mais do que isso, ele evidencia especialmente como a criação imagética do polonês se vale desse jogo de forças, especialmente aquele entre vida e morte - que surge em Kantor como uma figura que perfeitamente assume a importância que o Atlas tem para Warburg. O encenador nos atenta justamente para a pulsante dualidade presente aqui. Para ele, é exatamente a partir da morte que a vida pode se manifestar efetivamente na cena. Assim, assistimos não apenas à polaridade de "término" que a cena pode abarcar, mas também identificamos a polaridade de "transformação", que é inerente a sua simbologia - e que consecutivamente provoca estranheza no espectador.

Em seu ensaio, Didi-Huberman (2018) sugere que, ao elaborar algumas de suas ideias, Nietzsche (1844-1900) parece antecipar o "programa operatório" de Warburg no século passado. Dessa maneira, ao assinalar para a necessidade de problematizar o mundo para assim conhecê-lo, em A Gaia Ciência (1882), o filósofo consequentemente nos aponta para a necessidade de "dispor as coisas de tal maneira que a estranheza delas surja a partir de contatos tornados possíveis pela decisão de ultrapassar os limites de categorias preexistentes, dentro dos quais as coisas estavam mais calmamente organizadas" (Didi-Huberman, 2018, p. 118). Kantor parece absorver tais características de uma maneira muito semelhante à da Crítica dos Sentidos de Goethe. Assim, ele arranja e rearranja suas imagens distintas em uma espécie de caos, em uma montagem de enquadramentos que nunca estava salva de um remate.

Segundo Didi-Huberman (2018, p. 147), a Crítica de Goethe é justamente "destinada a não separar a atividade artística [...] da ciência e das disciplinas especulativas". Negando-se a colocar a arte e a ciência em oposição, ela tem o objetivo de mostrar que, sem o sujeito e o procedimento da experiência, não existirá um saber autêntico. Semelhante ao processo do desenho Caos de rochas de Luisenburg (1785), de Goethe, a análise que Kantor parece fazer de 
acontecimentos e experimentações produz variações de imagens do mesmo tema, que, com base em seu estudo, são colocadas em conjunto e processadas a partir do elemento da repetição, e assim ele desenvolve um método de metamorfose, ou de remontagem, que o artista procura sempre incentivar. Portanto, "a repetição envolve todos os dispositivos do teatro de Kantor e é procedimento decisivo na recriação da memória, no que talvez seja um dos eixos mais tensos de seu trabalho." (Greiner, 2015, p. 110).

O contraste entre atores desumanizados e bonecos de cera, feitos à imagem do homem, é um exemplo concreto de uma das apropriações mais presente no teatro kantoriano. Depois de diversas fases artísticas, o polonês entra em sua última fase, o Teatro da Morte, a qual poderíamos dizer que reúne características de todas as anteriores, em um acúmulo de pesquisas e experimentos. encenador escreve em 1975 um manifesto homônimo que marca sua concepção. Aqui sua pesquisa parece se concentrar em explorar a criação artística a partir do mito, das lembranças e da história. Como seu ponto de partida, Kantor encena sua obra-prima, A Classe Morta, realizada no mesmo ano, de onde se originam outros importantes trabalhos na carreira do encenador.

A partir de uma leitura de Didi-Huberman (2018), vemos como o método de criação de Kantor também pode ser comparado ao que ocorre em um importante trabalho de Francisco de Goya (1746-1828), o quadro O sonho da razão produz monstros (1797), assim como em sua Linguagem Universal. O que notamos essencialmente é que a relação entre as imagens kantorianas não se dá somente na ordem da semelhança e tensão, mas também na de imaginação e razão. O elemento do grotesco, presente tanto nos trabalhos de Kantor como no de Goya (vide Figura 7 e Figura 8), e a colisão entre os elementos do fantástico e os espaços familiares - em Goya sendo sua mesa de trabalho e em Kantor os espaços de sua juventude (como a sala de aula) - aproximam claramente os dois artistas.

Um ponto interessante nesse diálogo de obras são os "excessos", analisados por André Malraux (1901-1976) no desenho de Goya, que podem igualmente ser encontrados nas peças de Kantor. A essência do caos, produzida pelo contraste entre bonecos de cera (feitos à imagem do homem) e atores desumanizados em 
cena, os "monstros" de Kantor, nos remete àqueles monstros da razão de Goya ambos parecem desejar sair de seu estado de sonho para se tornarem reais. Isso ocorre porque, como comenta Baudelaire, os monstros de ambos são verossímeis: Goya tem em seus animais as feições humanas, enquanto Kantor potencializa a vida humana em corpos que aparentam estar sem vida alguma.

É perceptível que Goya deseja trazer um testemunho da verdade em seu trabalho, algo que Kantor não tem interesse, a não ser o da própria realidade. Porém, partindo da classificação que Didi-Huberman faz de Goya, apontando a imaginação como uma "linguagem universal", é notável que, assim como o Atlas de Warburg carrega o mundo para ser seu maior conhecedor, Kantor carrega a imaginação ligada com suas lembranças para criar "monstros", seus icônicos personagens mortos-vivos. Estes, como os de Goya, são mais do que uma imagem pessoal; apresentam-se, segundo Didi-Huberman (2018, p. 140), como uma "reflexão fundamental sobre as potências da imaginação no homem, reflexão que empresta seu próprio método a seu objeto, a imaginação pensada como instrumento [...] de um verdadeiro conhecimento crítico do corpo e do espírito humanos". 
Figura 7 - Quadro "O sonho da razão produz monstros", de Francisco Goya (1797-1799)10 Figura 8 - Cena do espetáculo “A Classe Morta” (1975), de Tadeusz Kantor Foto: George Oliver"11

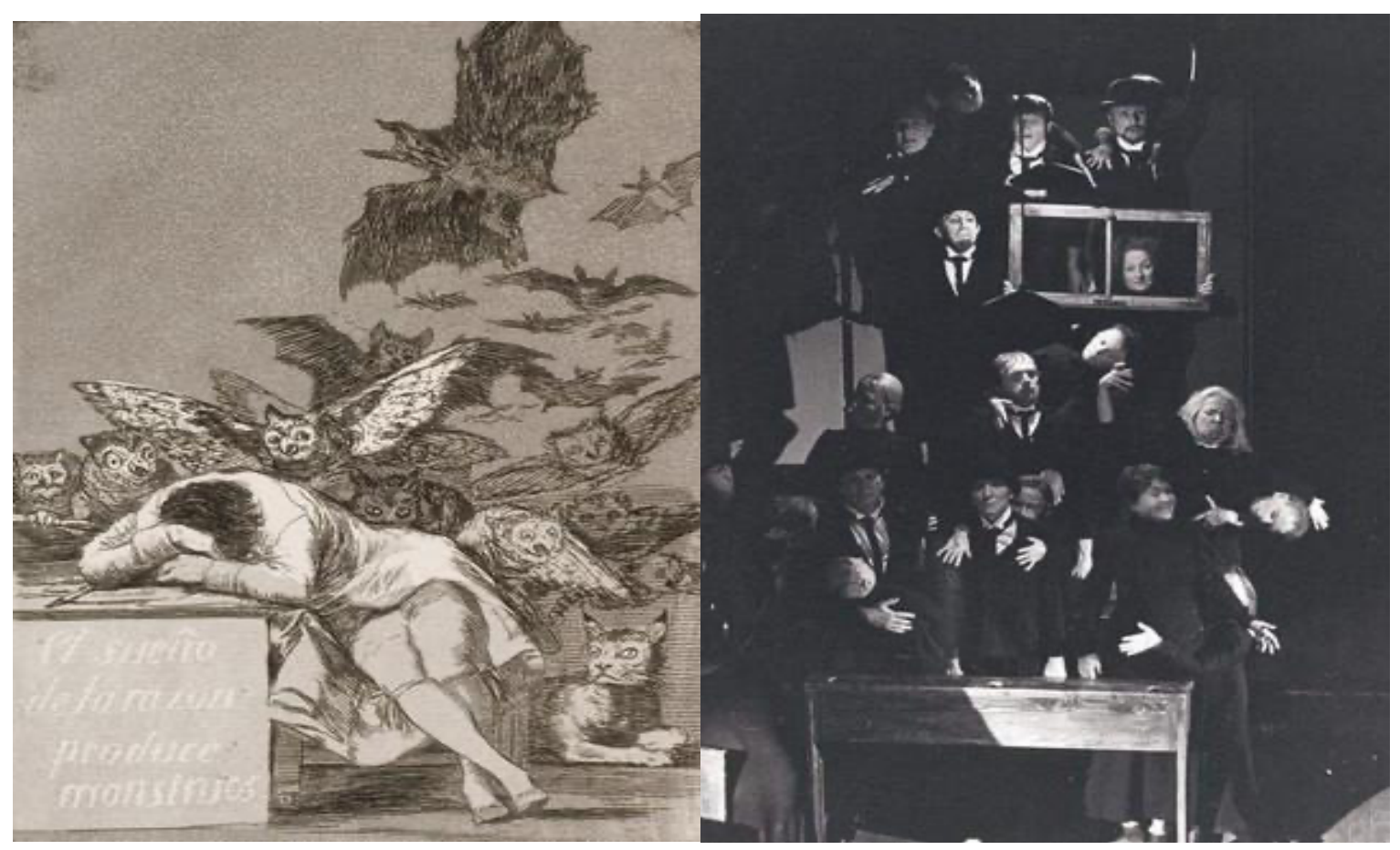

Didi-Huberman ainda nos leva à Freud (1856-1939), que, ao analisar o texto sobre o retorno travestido dos deuses, de Heinrich Heine (1853), comenta acerca da potência grotesca capaz de, consequentemente, gerar "certo mal-estar". Assim, por meio de uma colagem de elementos teatrais, Kantor procura ultrapassar os limites da aquisição de conhecimento, mantendo viva a estranheza, bem como mostrar como a experiência do saber é incorporada a uma experiência pessoal. O encenador - que, juntamente de Warburg, faz parte do Atlas de uma época temerosa - parece ter muito em comum com o Atlas moderno, que na época de guerra se torna o judeu errante, transformado em um pária por excelência. Um sem-nome exilado, caçado e sem casa, como a própria Polônia e o homem carregando malas de Kantor, diagnosticado com uma doença que nada mais é que

${ }^{10}$ Disponível em: https://www.italianways.com/rebel-gods-punishment-the-farnese-atlas/. Acesso em: 5 dez. 2019.

${ }^{11}$ Disponível em: http://www.demarco-archive.ac.uk/assets/9629-1976 kantor dead class edinburgh. Acesso em: 5 dez. 2019. 
o mal social e destinado a carregar sozinho sobre os ombros todo o peso do sofrimento.

Um enorme paralelo fica evidente nas obras warburguiana e kantoriana: no primeiro, com a figura do Atlas, identificamos o sofrimento de portar e a potência do conhecer; no segundo, em sua principal temática, o sofrimento de morrer e a potência da transformação. Eis os polos perfeitamente capazes de aflorar toda a potencialidade de uma imagem, que automaticamente retira do espectador aquela mera recepção contemplativa, constituindo a dialética necessária para atualizar suas significações nestes novos tempos. Onde o Atlas luta repetidamente contra a queda e, assim, adquire mais conhecimento, Kantor usa a repetição para projetar a memória além do esquecimento, também suscitando um saber novo, sempre capaz de gerar outras conexões. Assim, consolidamos essa fecunda intersecção entre trabalhos que, acima de tudo, parecem destacar essa força viva que nasce da escolha do artista - transcendendo a imagem para além de seus limites preestabelecidos.

Contudo, é possível que Kantor tenha de fato o que Didi-Huberman (2018, p. 174) chama de Gaio Saber Inquieto, um "saber do heterogêneo por 'eleger' domicílio em sua afinidade com o outro, objeto ou sujeito", esse amor a seu dessemelhante. Assim, utilizando as imagens para inquietar seu espectador por meio de combinações provocantes, Kantor também procura a transgressão das fronteiras e tem o desejo de conhecer o dessemelhante através de constelações, assim como Warburg. Diante de tudo, todo esse movimento de aproximação entre essas obras reforça ainda mais a potência do método da montagem na obra kantoriana e no Atlas Mnemosyne, sempre capazes de evidenciar relações que vão muito além da convenção e da linearidade temporal.

\section{Referências}

AUMONT, Jacques. A imagem. Campinas: Papirus, 2012.

CINTRA, Wagner. A dramaturgia da imagem no teatro de Tadeusz Kantor. Rebento: Revista de Artes do Espetáculo, n. 2, p. 88-98, 2010. 
DIDI-HUBERMAN, Georges. Atlas ou o Gaio Saber Inquieto: o olho da história, III. Trad. de Márcia Arbex e Vera Casa Nova. Belo Horizonte: Ed. UFMG, 2018.

DIDI-HUBERMAN, Georges. Quando as imagens tocam o real. PÓS. Revista do Programa de Pós-Graduação em Artes da EBA/UFMG, v. 2, n. 4, p. 206-219, 2012.

EISENSTEIN, Sergei. A forma do filme. Rio de Janeiro: Jorge Zahar, 2002.

GREINER, Christine. No limite do sonho, uma infiltração tóxica em objetos, vidas e corpos. In: Máquina Tadeusz Kantor. São Paulo: Sesc São Paulo, 2015. (Catálogo da exposição realizada no Sesc Consolação, em São Paulo, de 19 ago. - 14 nov. 2015).

GUINSBURG, Jacob. Apresentação. In: KANTOR, Tadeusz. O teatro da morte. São Paulo: Perspectiva, 2008.

JOLY, Martine. Introdução à análise da imagem. Campinas: Papirus, 2012.

KANTOR, Tadeusz. O teatro da morte. São Paulo: Perspectiva, 2008.

KOBIALKA, Michal. Kantor está morto! Esqueçam Kantor! Sala Preta, São Paulo, v. 5, p. 225-232, 2005.

LEHMANN, Hans-Thies. Teatro pós-dramático. Trad. de Pedro Süssekind. São Paulo: Cosac Naify, 2007.

LUDUEÑA, F. La ascensión de Atlas: glosas sobre Aby Warburg. Buenos Aires: Mino y Davila, 2017.

SUCHAN, Jarosław. A máquina Kantor. In: Máquina Tadeusz Kantor. São Paulo: Sesc São Paulo, 2015. (Catálogo da exposição realizada no Sesc Consolação, em São Paulo, de 19 ago. - 14 nov. 2015).

Recebido em: 15/10/2020

Aprovado em: 27/01/2021 